\title{
Anthós
}

\section{The World and Bollywood: An Examination of the Globalization Paradigm}

Jonathan R. Miller

Portland State University

Follow this and additional works at: https://pdxscholar.library.pdx.edu/anthos

Part of the Other International and Area Studies Commons Let us know how access to this document benefits you.

\section{Recommended Citation}

Miller, Jonathan R. (2015) "The World and Bollywood: An Examination of the Globalization Paradigm," Anthós: Vol. 7: Iss. 1, Article 5.

https://doi.org/10.15760/anthos.2015.27

This open access Article is distributed under the terms of the Creative Commons Attribution-NonCommercialShareAlike 4.0 International License (CC BY-NC-SA 4.0). All documents in PDXScholar should meet accessibility standards. If we can make this document more accessible to you, contact our team. 


\section{The World and Bollywood: An Examination of the Globalization Paradigm}

Jonathan R. Miller

\section{Introduction}

Since its advent in the beginning of last century, the Indian film industry, or "Bollywood," has played an integral role in both the expression of social frustration, and the formation of national identity. This was true in the 1930s when the caste system "became a central issue of cinematic exploration" (Gokulsing and Dissanayake, 2004, p. 10), and after the 1947 partition when "the important role that Indian films have played in building nationhood" (Gokulsing and Dissanayake, 2004, p. 13) became apparent. After the 1991 liberalization of the Indian economy, Indians both at home and abroad were faced with a rapidly changing social structure as a changing economic system had its effect on societal norms. Here too film fulfilled its role as societal narrator and influencer, and significantly impacted the way in which modern Indians understand their position in a global context.

Through examining film's role as a social commentator and agent, the issue of outlining a theoretical framework within which one measures changes within India and its diaspora is a complex task. Is globalization adequate to describe India's increasing interconnectedness with the world? Is the Liberalization moniker too direct? Can postmodernism be invoked in a way that provides an abstract perspective on the very concrete consequences of a changing India? For several Bollywood scholars, the globalization label is enough. However, to limit the discussion to the globalization paradigm is to leave the complexity of film's role in society aside, in favor of a more expedient, and perhaps more palatable answer.

Rajinder Kumar Dudrah's work, Sociology Goes to The Movies, views Bollywood from a sociological perspective, and provides the 
globalization paradigm as setting within which one may understand the content of Bollywood films. As will be illustrated, such a perspective is an understandable first step, but the process of disproving the applicability of the globalization paradigm is what illuminates the nature and role of Indian film in Indian society.

\section{Globalization}

When discussing the increasing interconnectedness of society in the modern world, the application of theoretical paradigms must place the subjects within their proper global context, a daunting task considering the polarizing nature of academic discourse surrounding these topics. Among the most contested and controversial is the concept of 'Globalization.' Mauro F. Guillén, in his examination of a variety of views on globalization, proposes to "combine the perspectives of [Roland] Robertson and [Martin] Albrow, and so define globalization as a process leading to greater interdependence and mutual awareness (reflexivity) among economic, political, and social units in the world, and among actors in general." This combination is particularly astute, as Robertson's "...intensification of consciousness of the world as a whole" highlights the 'reflexivity' of global interactions which result from Albrow's "...diffusion of practices, values and technology..." (Guillén, 2001, p. 4). Reflexivity being key to our operational definition of globalization, herein lies a major dysfunction in the analysis of Indian Cinema. Namely, that 'Globalization' is treated as though it is a unidirectional and transitive move by an individual actor, without requiring the reflexivity of that which is acted upon.

Take for instance Dudrah's commentary immediately preceding a discussion of the liberalization of the Bollywood film industry: "The use of referents from Hollywood cinema by Bollywood cinema and vice versa $[\ldots]$ needs to be situated within the context of the globalisation of film [...]" (Dudrah, 2006, p. 148). First, the context Dudrah places his discussion in is liberalization rather than globalization, creating the inference that he is conflating the two. Liberalization is the process of altering a given economic model so that it more closely conforms to models that arise from a distinctly European economic history; so the globalization that Dudrah describes is actually a unidirectional transfer of economic values and 
guidelines from one society to another. Secondly, while Dudrah does give lip service to the reflexivity of globalization through the "vice versa' portion of his statement, he provides no actual evidence of Hollywood incorporating Indian economic or cultural values. $\mathrm{He}$ speaks extensively to Hollywood and Bollywood taking on joint financial and creative ventures, but these are limited to ventures within Bollywood's existing market (Dudrah, 2006, p. 148-155). In other words, while Hollywood can influence and take part in Bollywood, Bollywood's access to Hollywood has not necessarily increased to the same extent.

Dudrah's conflation of globalization and liberalization is problematic, however he identifies the nature of the Bollywood/Hollywood relationship accurately and neutrally. It is perhaps this neutrality that brings about his misuse of globalization. For while liberalization carries the inference of the unidirectional transfer of thought and practice, globalization infers a more reciprocal relationship; and is therefore, perhaps, less controversial. While this writing examines Dudrah's work, this is due to the fact that the complexity of his work lends itself to analysis; he is certainly not the worst abuser of the globalization label in the Bollywood discourse. Consider the following, taken from a 2003 issue of World Literature today, which provides a brief overview of Bollywood cinema: "the Indian film industry continues to hold its own despite Hollywood's aggressive globalization, which frequently means the erosion of autonomy and self-determination in developing markets" (Jaikumar, 2003 , p. 24). Here we not only see a lack of reflexivity; but a perversion of Albrow's concept of diffusion. Rather than an almost passive expansion of a Hollywood style of operation, we see a projection of power. When comparing this author's invocation of "Hollywood's aggressive globalization" to Dudrah's more passive "globalisation of film," it becomes difficult to tell whether Dudrah is being more neutral, or simply less honest.

\section{Postmodernism and Globalization}

In Sociology Goes To The Movies, Dudrah (2006) employs globalization extensively, and describes "the social processes of globalization - the expansion of capital and capitalism, the compression of time and space, increased cultural commodification, 
the interactions between the local and the global, all increasingly occurring in and indicative of the late modern era" (p. 40). In constructing his definition of Globalization, Dudrah cites the work of David Harvey, Frederic Jameson, and Saskia Sassen. These particular choices in authorship are rather odd when considering the resultant definition. First, both Harvey and Jameson's referenced writings focused on 'Postmodernism', which, as Jameson describes, is "the reflex and concomitant of yet another modification of capitalism" (Stucky, 1993, p. 216). Therefore, Dudrah's conception of the "social processes of globalization" is in large part based on a paradigm where social processes are subordinate to economic ones, severely undermining his concept of globalization as whole. Secondly, even if we ignore his problematic application of Harvey and Jameson's writings, his use of Sassen's work undermines a core premise pulled from Harvey and Jameson; namely, the "compression of time and space." As one reviewer put it, "according to Sassen, place and 'placeboundedness' continue to matter in today's global economy more than many observers admit" (Carriere, 1999, p. 841). This dissonance in views seriously calls into question how stable his definition can be, although its source is easily determined. The internal conflict in Dudrah's definition stems from a conflation of the Globalization paradigm, and the Postmodernism paradigm. Postmodernism, in accordance with Harvey and Jameson, is an overarching theory of the operation of global society based on 'advanced capitalism'; advanced capitalism is to the current postmodern era what the Enlightenment was to the modern era. In contrast, Globalization is a paradigm that operates within the postmodern paradigm. Sassen's emphasis on the relevance of place can comport with Harvey and Jameson's description of postmodernism because the relevance of place within Globalization does not discount the world's increasingly interconnected nature. In fact, it would not be possible to weigh the importance of 'placeboundedness' against the importance of interconnectedness if that interconnectedness did not exist in the first place. Therefore, Dudrah's inadequate description of globalization is not so due to a conflict between globalization and postmodernism, but from the conflation of those theories. 


\section{Clarifying Dudrah}

Taking what we know of Dudrah's 'globalization,' what then is the impact on interpreting his work? For simplicity's sake, let us consider the relationship between Bollywood and Hollywood. According to Dudrah, "The use of referents from Hollywood cinema by Bollywood cinema and vice versa [...] needs to be situated within the context of the globalization of film wherein production techniques, finance and aesthetic sources are increasingly being brought into contact with each other from different parts of the same production centres as well as from around the world" (Dudrah, 2006, p.148). Through the lens of Guillén's definition of Globalization, I examine Dudrah's discussion of economic and social globalization. Bearing in mind Guillén's consideration of politics within his definition, they are also considered within this analysis; although are perhaps emphasized to a lesser degree as was done by Dudrah. In doing so, I place a special emphasis on identifying evidence of 'reflexivity' between Bollywood and Hollywood so as to differentiate between points where Dudrah misapplies globalization, and points where the globalization paradigm is accurately identified.

\section{Economic Globalization: Liberalization of Film Financing}

In May 1998 Bollywood was conferred official status as an industry, and so began the liberalization of that industry (Dudrah, 2006, p. 148). According to Ganti (2013), "until the advent of industry status and corporatization, the finance for filmmaking in India was predominantly connected to the vast unofficial or "black" economy" (p. 64). Prior to liberalization, Bollywood films were funded through unregulated networks of financiers, whose occupations varied and included both legitimate and criminal enterprise. There were two primary economic consequences to liberalization: filmmaking in India was professionalized and "began to appear and operate more in line with dominant understandings of professional organization and discipline" (Ganti, 2013, p. 65), and foreign capital and media companies themselves began to make their appearance (Dudrah, 2006, p. 151).

At first glance there are clear indications of the relevance of the globalization paradigm. The Bollywood film industry's economy post-liberalization does interact with and benefit from Hollywood's. 
Therefore, in a sense, we do see reflexivity here. However, this reflexivity is limited to economic cooperation within the context of a liberalized system. In other words, we see contact between the industries of Bollywood and Hollywood, however the terms of that contact are dictated by an economic system that has been imported. In a 2008 open letter to Hollywood, Karan Johar, a Hindi film producer highlights some of the differences between the Bollywood and Hollywood systems; noting that "relationships are stronger than contracts" (Ganti, 2013, p. 56). The intent was to advise Hollywood studios interested in Hindi film production on what they were getting themselves into, as Bollywood and Hollywood "are not organized similarly nor have they operated in the same way" (Ganti, 2013, p. 57). Johar's commentary may have held true over the majority of Bollywood's history, however the changing economic landscape is relegating his sentiment to the realm of nostalgia. "Film makers such as Shekhar Kapur and Yash Chopra have gone on record claiming that the corporatization of film-making will damage the creative culture of commercial film-making in India" (Dudrah, 2006, p. 149). If Johar's commentary truly carried any weight, Chopra and Kapur would have had nothing to be concerned with, as the economic framework of film in India would have remained unchanged. Under a liberalized system, Hollywood is less bound by Bollywood's modus operandi, and therefore gains a degree of advantage over local producers who may have incorporated liberal practices comparatively recently. Furthermore, Johar's commentary presumed that Hollywood was entering an entirely new economic arena, which was not necessarily true. "American films (sometimes dubbed in Hindi) started reappearing in Indian theatres after a new agreement was signed between the Government of India and Motion Picture Producers and Distributors of America, Inc. (MPPDA) in April 1985" (Gopalan, 2002 , p. 5). Therefore, Hollywood not only had an advantage in a liberalized system, but over ten years of experience in coordinating with film distributors inside India; utilizing the very networks that Johar presumed they would have difficulty navigating. At a state level, liberalization of the Indian economy had only begun seven years prior to the film industry, in response to the external debt crisis of 1991. Liberalization was conducted in a way that conformed "with the orthodoxy of the IMF and the World Bank [replicating] broadly 
the response of several developing countries in Latin America and sub-Saharan Africa to the debt crisis in the 1980s" (Nayyar, 1998, p. 3127). India in particular is held up as a success story by advocates for IMF and World Bank economic rescue, or 'structural adjustment,' as an example of how effective the method is for promoting economic growth (Babb, 2005, p. 134).

The question here however, is not whether or not economic reform has been successful, but whether or not the repair of the Indian economy, through the application of non-Indian economic policy, constitutes globalization. Bollywood's economic transformation is a consequence of the supplantation of the 'black' system with a system that not only reflects foreign perspectives; but whose changes clearly favor foreign industry by operating under rules with which they are already familiar. This type of restructuring may foster economic integration, but it also removes the need for Hollywood to act 'reflexively' to a foreign economic system. The result leans more towards postmodernism than globalization, for while the systems are interacting, that interaction is made possible by Bollywood changing the local economic landscape, and not by Hollywood adapting Indian practices.

\section{Social Globalization: Pardes and the Diaspora}

As the effects of liberalization reshaped the economic landscape, so too was the social sphere equally affected. According to Ganti (2013), "the transformed economic scenario [allowed for] the rapid rise of consumerism, increase in the numbers of a visibly consuming middle class, and the burgeoning televisual landscape" (p. 66). It is within this televisual landscape that film portrays the volatility of Indian modernity; and, according to Ingrid Therwath (2010), "exaggerate[s] features but also paradoxically dictate[s] patterns of normality. In this sense, they shape and impose exemplarity by broadcasting role models, figures of idealization and identification at once. Popular cinema is thus a major actor of social engineering" ( $p$. 2). Therwath's writing 'Shining Indians': Diaspora and Exemplarity in Bollywood takes a detailed look at how the portrayal of Nonresident Indians (NRI), or Indians in diaspora, transformed during the years after liberalization. It was during this transition that NRI 'ceased to be a symbol of the 'Other' and has become instead the 
prototype of the new Indian, globalized and modern, but always a nationalist at heart" (Therwath, 2010, p. 6). By taking this more positive role in the midst of liberalization, "the romantic or family comedies with a NRI hero sell 'Brand India' to the world while furthering the cause of capitalism and social conservatism in India" (Therwath, 2010, p. 10). The cinematic representations of diasporic Indians served as "deterritorialized models of national identity" (Therwath, 2010, p. 5), simultaneously supporting the acceptance of liberalization efforts at home and lionizing the adoption of liberal habits by those in the diaspora. When considering Therwath's work, it is clear that the role that diasporic film is taking on is not that of a globalizer, but that of a liberalizer.

When Dudrah describes the shift in views on the diaspora during the liberalization period, he identifies the same points that Therwath does; but he orients his discussion toward what values film is representing rather than propagating (Dudrah, 2006, p. 66-83). Through discussion of his study of the 1997 film Pardes, Dudrah illustrates the ways in which the film's characters reflect the interaction between India and the Diaspora. Pardes revolves around Ganga, a rural Indian woman who finds herself in America due to an arranged engagement. Her intended husband, Rajiv, is the son of a wealthy diasporic Indian and is distinctly anti-Indian; he embodies a love of the excesses allowed for by western culture and openly despises Indian tradition. Rajiv's father arranges the engagement via his adopted son Arjun, hoping that Ganga may serve as a connection between Rajiv and his cultural heritage. Arjun, as a consequence of his role as matchmaker, develops a love for Ganga and so forms the final piece of a love triangle that examines the roles of those involved. Over the course of the film, Rajiv and Ganga are found to be consistently incompatible and, according to Dudrah, "represent the irreconcilable ends of pardes [diaspora] and des [India] respectively" (Dudrah, 2006, p. 80). Arjun on the other hand is compatible with Ganga, which Dudrah attributes to their mutual comfort "in the ways of pardes (the US), minus its excesses" and identifies the fact that they "respect and communicate the ideals of des (India)..." as positioning them for a lasting union (Dudrah, 2006, p. 80). In spite of the incompatibility of the two extremes, Ganga, and by extension the traditional Indian, is shown as being compatible with life in the 
diaspora when tradition is balanced with host culture, as is embodied by Arjun.

Dudrah's choice to limit his analysis to what Pardes is representing rather than propagating is what justifies his invoking globalization, but this only works relative to who is actually viewing a given film. Take for instance the following commentary from one of Dudrah's respondents:

Kully: Like when I watched Pardes I asked my mum is this how it is in India, how it's shown in the film. Sometimes she agrees with the film, at other times she doesn't. If she doesn't then I'll just take it in for myself and it's interesting to see how they portray India and Indian things. (Dudrah, 2006, p. 73)

Here we see a member of the Indian Diaspora who has not been to India, a second generation NRI, relating how they view and understand the content of Pardes. Being second generation, this individual's identity formation has taken place within a dual-cultural context. Rather than having their identity challenged externally by new cultural inputs, cultural conflicts occur internally and dialectically to form a sense of self. In this case, with this viewer, Pardes is representative of globalization in that it reflects multicultural, or socially globalized, identities and characters through the experience of Arjun and Ganga. However, if we change the viewership to first generation NRIs or Indians still residing in India, then Pardes is representative of liberalization; as that particular viewership will assess the effects of new cultural inputs on long held traditions. Therefore, when placing diasporic film in the context of globalization, Dudrah's analysis is not incorrect, just incomplete. Dudrah notes that, for those in diaspora, film offers "select possibilities in the formation of their subjectivities" (Dudrah, 2006, p. 83), but does not explore how those changing subjectivities may affect the behavior of diasporic communities. In choosing not to make the leap from what Pardes is representing to how it may influence behavior and identity, Dudrah fails to identify its potential for liberalization. 
While films like Pardes do carry a liberalizing potential, the evolving portrayal of diasporic Indians may make Dudrah's globalization conjecture more applicable in the future. As a major actor of social engineering, popular cinema served as a tool for popularizing liberalization between the early 1990s and mid 2000s. Diasporic Indians have been an effective medium for doing this, as positive portrayals of those living in liberalized society validates liberal reform within India. However, constructing a deterritorialized national identity requires a cultural exchange between all involved; a process that mimics globalization in that it develops reflexivity, but is separate from it, as it constitutes cultural reflexivity between Indians and the Indian diaspora and not between that community and the rest of the world. Therefore, both liberal and conservative ideals must maintain a degree of influence to facilitate the formation of a common identity. As the liberalization of the Indian economy was a transformative process, it is not surprising that liberal ideals took center stage during the process' formative years, however this is changing. Therwath notes that NRIs are "not necessarily objects of envy or role models anymore" as their portrayal since the mid-2000s has been more negatively associated with less socially conservative activities (Therwath, 2010, p. 12). This change in their portrayal represents the assertion of those conservative ideals within the deterritorialized national identity as the presence of liberalism within that identity normalizes. Rather than a positive portrayal of the diaspora motivating India's residents to liberalize, their negative portrayal invites the diaspora to Indianize, thereby solidifying a common deterritorialized national identity. If this is truly the case, then Dudrah's globalization conjecture, however partial, may prove more applicable as the liberalizing potential of diasporic film decreases alongside continued representations of life in the diaspora. Indeed, if Therwath's concept of a deterritorialized national identity is truly taken to heart, and that national identity remains influenced by liberalization; then many Indians, regardless of physical location, may eventually embody a similar identity to that of the second generation NRIs; and therefore embody a sense of self that at least approaches the globalization paradigm. 


\section{Network Society and the Diasporic Feedback Loop}

While the previous scenario may approach the globalization paradigm, the concept of a deterritorialized national identity that allows for its potential existence in the future essentially defeats it in the present. To illuminate this we turn to Manual Castells' Toward a Sociology of the Network Society, where he contends that a new global society is taking shape alongside the new global economy; and that this society is made up of networks. This network society is made possible by technical advancements like the Internet, which have overcome the "inability of networks to manage complexity beyond a critical size" that prevented them from overtaking the usefulness of centralized apparatuses in coordinating society previously (Castells, 2005 , p. 248). Within this, Castells makes reference to the concept of a "Global City," defining it as consisting of "territories that in different cities ensure the management of the global economy and of global information networks" (Castells, 2005, p. 250). According to Dudrah, Bollywood's global presence is increasing rapidly for two reasons: "first, because the media-lines of dissemination are proliferating [...and... second,] the increase in the types of media: digital, satellite, air, print, Internet, radio, optical cables, digital subscriber lines (or DSL), and telephone" (Dudrah, 2006, p. 101-102). These media-lines of dissemination manage the economics of Bollywood within the global economy by moving capital and goods to and from new markets, while new technologies increase the modes through which consumers may access those goods; and therefore forms a 'global information network' of Indian culture which may be accessed and leveraged.

Dudrah's description of what has increased the global presence of Bollywood does share similarities with Castells' description of components of the global city, but the deterritorialized national identity that Bollywood film fosters works counter to interconnectivity between Indian cinema and 'neighboring' components within the global city. In constructing that identity, there is a necessary delineation between who does or does not identify with that new model; a clear consequence of which is the lack of popularity of Bollywood film among non-Indian audiences. According to a 2012 UNESCO report, India out produced all other nations in 2005,2006,2008, and 2009; but out of the 5891 films 
produced between 2005 and 2009 only the 2008 film Slumdog Millionaire achieved global popularity (Achland, 2012, p. 5,8). Slumdog Millionaire itself is a questionable representation of Bollywood cinema, as it was directed by Danny Boyle, an English director; written by Simon Beaufoy, an English writer; and produced by Fox Searchlight, an American studio (Box Office Mojo, n.d.). As with audiences, filmmakers outside of the Bollywood industry incorporate very few Bollywood elements in their films. In fact, the only direct reference to Bollywood's influence on Hollywood comes in the form of commentary by director Baz Luhmann; who "has openly agreed that he is influenced by Bollywood" (Ghosh, n.d.). Luhmann's 2001 movie Moulin Rouge is held up as evidence of Bollywood's influence, however it stands as the only evidence. Therefore, while Bollywood maintains a presence within the global city through the Indian diaspora, the impact of Bollywood on its global neighbors is negligible at best.

This issue of interconnectivity between global city components, or differing industrial networks from a Castellsian point of view, is perhaps a shared flaw in Castells and Dudrah's lines of reasoning. For while different industries and cultures are increasing their global presence, the degree to which they are mutually reflexive to one another is a necessary measure of how globalized a society is. Castells does not address reflexivity of one industrial network to another, in much the same way that Dudrah does not place significant importance upon Bollywood's social impact, or lack thereof, on the societies within which diasporic viewership maintains a presence. Dudrah's choice to avoid this discussion is perhaps motivated by the lack of evidence that would support such an analysis. Herein lies a major issue in calling the Bollywood industry globalized, or classifying it as a force of social globalization. Bollywood is absolutely located within the global city, and as a "major actor of social engineering" it certainly has an effect upon diasporic Indian identity. However, as that effect is limited to those audiences and does not extend significantly to host societies, it operates as an agent of nationalization rather than globalization. Furthermore, this effect compounds upon itself. For while the production of films that reflect diasporic values support efforts of liberalization within India, they also serve to validate and reinforce the acceptance of those values 
within diasporic communities, as exemplified by the relative ease with which Dudrah's respondents identify with movies like Pardes. As newly produced films continuously re-present the state of diasporic identity, they are simultaneously re-presenting an evolving liberalized lifestyle as diasporic Indians modernize over time; creating a diasporic feedback loop that advances a deterritorial model of national identity. This is exemplified by both the rapid increase in popularity of diasporic film, and the waning popularity of the same. Therwath notes that, "since the mid-2000s, while NRIs continue to bring in money at the box-office and therefore to assert their presence-albeit often negative-on the big screen, they are not necessarily objects of envy or role models anymore" (Therwath, 2010, p. 12). If we consider Bollywood to be an actor of social engineering, then the rapid liberalization interests presented between the early 1990s and mid 2000s are just as significant as conservative interests presented in more recent films. This conservatism presents a conservative modernized identity rather than a traditional one, and therefore reinforces the place of liberal values within global Indian society. The status of diasporic Indian characters in film reverting to a source of contempt for over-modernizing does not diminish their influence on identity formation, it only redirects that influence in a way that preserves conservative values within the modern Indian identity.

\section{Conclusion}

In situating Bollywood film within the context of Globalization, Dudrah portrays an industry that is increasingly connected and reflexive to global issues. In this he is successful, for as has been illustrated here, Bollywood is very much a part of the global narrative. However, while Bollywood's industrial and cultural footprint is well established within the global city, the cultural exchange between Bollywood and its global neighbors is negligible at best, and is therefore less indicative of globalization than it is of other more suitable, although perhaps less palatable, paradigms. Globalization in and of itself carries connotations of general interconnectedness, so when describing a given industry's increasing presence in the world it is tempting to apply the globalization moniker as a badge of progress. However, such an approach risks undermining objective analysis in 
favor of positivism. In this case, conflation of the globalization paradigm with postmodernism and liberalization provides a skewed perspective on the cultural impact of the film industry, cutting the conversation short and generalizing Bollywood's impact to such a degree that issues of identity formation as they relate to liberalization and migration are left unexamined. This would be less of an issue if Dudrah's area of focus were along the same lines as literary analysis. However, as his book is titled Sociology Goes to the Movies, limiting the discussion to film as reflective of society rather than formative of society is simply not enough.

\section{References}

Achland, C. (2012). From International Blockbusters to National Hits: Analysis of the 2010 UIS Survey on Feature Film Statistics. UNESCO. Retrieved from http://www.uis.unesco.org/culture/Documents/ib8-analysis-cinemaproduction-2012-en2.pdf

Babb S. (2005). The Social Consequences of Structural Adjustment: Recent Evidence and Current Debates. In G. Ritzer and Z. Atalay (Eds.), Readings in Globalization: Key Concepts and Major Debates (pp. 127-138). USA: WileyBlackwell.

Box Office Mojo (n.d.). Slumdog Millionaire: Summary. Box Office Mojo. Retrieved from http://www.boxofficemojo.com/movies/?id=slumdogmillionaire.htm

Carriere M. (1999). Globalization and Its Discontents: Essays on the New Mobility of People and Money. By Saskia Sassen [Review of the book Globalization and Its Discontents: Essays on the New Mobility of People and Money, by S. Sassen]. International Affairs (Royal Institute of International Affairs 1944-), 75(4), 841. Retrieved from http://www.jstor.org/stable/2626305

Castells, M. (2005). Toward a Sociology of the Network Society. In G. Ritzer and Z. Atalay (Eds.), Readings in Globalization: Key Concepts and Major Debates (pp. 246-252). USA: Wiley-Blackwell.

Dudra, R. K. (2006). Sociology Goes To The Movies. New Delhi, India: Sage.

Ganti, T. (2013). Routledge Film Guidebooks: Bollywood (2 ${ }^{\text {nd }}$ ed.). New York, NY: Routledge.

Ghosh, P. (n.d.). Are Hollywood and Bollywood movies influencing each other? Official Blog of TheScreenplayWriters.com. Retrieved from http://www.thescreenplaywriters.com/blog/are-hollywood-and-bollywoodmovies-influencing-each-other/

Gokulsing, K., \& Dissanayake, W. (2004). Indian Popular Cinema: A Narrative of Cultural Change. Trent, UK: Trentham Books.

Gopalan, L. (2002). Cinema of Interruptions: Action Genres in Contemporary Indian Cinema. London: British Film Institute. 
Guillén, M. F. (2001). Is Globalization Civilizing, Destructive or Feeble? A Critique of Five Key Debates in the Social Science Literature. In G. Ritzer and Z. Atalay (Eds.), Readings in Globalization: Key Concepts and Major Debates (pp. 4-17). USA: Wiley-Blackwell.

Harvey, D. (1989). The Condition of Postmodernity. Cambridge, Massachusetts: Blackwell.

Jaikumar, P. (2003). Bollywood Spectaculars. World Literature Today, 77(3/4), 2429. Retrieved from http://dx.doi.org/10.2307/40158170

Jameson, F. (1991). Postmodernism or the Cultural Logic of Late Capitalism. Durham, North Carolina: Duke UP.

Nayyar, D. (1998). Economic Development and Political Democracy: Interaction of Economics and Politics in Independent India. Economic and Political Weekly, 33(49), 3121-3131. Retrieved from http://www.jstor.org/stable/ $\underline{4407443}$

Sassen, S. (1998). Globalization and Its Discontents: Essays on the New Mobility of People and Money. New York: New.

Stucky, D. (1993). Postmodernism, or the Cultural Logic of Late Capitalism by Fredric Jameson [Review of the book Postmodernism, or the Cultural Logic of Late Capitalism, by F. Jameson]. Utopian Studies, 4(2), 216-217. Retrieved from http://www.jstor.org/stable/20719983

Therwath, I. (2010). 'Shining Indians': Diaspora and Exemplarity in Bollywood. South Asia Multidisciplinary Journal, 4. Retrieved from http://samaj. revues.org/3000 